\title{
Introducing a rainfall compound distribution model based on weather patterns sub-sampling
}

\author{
F. Garavaglia ${ }^{1}$, J. Gailhard ${ }^{1}$, E. Paquet ${ }^{1}$, M. Lang $^{2}$, R. Garçon ${ }^{1}$, and P. Bernardara ${ }^{3}$ \\ ${ }^{1}$ EDF - DTG, 21 Avenue de l'Europe, BP 41, 38040 Grenoble Cedex 9, France \\ ${ }^{2}$ HHLY, CEMAGREF, 3bis quai Chauveau, CP220, 69366 Lyon Cedex 09, France \\ ${ }^{3}$ EDF - R\&D LNHE, 6 quai Watier, 78401 Chatou, France
}

Received: 15 December 2009 - Published in Hydrol. Earth Syst. Sci. Discuss.: 15 January 2010

Revised: 1 May 2010 - Accepted: 1 June 2010 - Published: 16 June 2010

\begin{abstract}
This paper presents a probabilistic model for daily rainfall, using sub-sampling based on meteorological circulation. We classified eight typical but contrasted synoptic situations (weather patterns) for France and surrounding areas, using a "bottom-up" approach, i.e. from the shape of the rain field to the synoptic situations described by geopotential fields. These weather patterns (WP) provide a discriminating variable that is consistent with French climatology, and allows seasonal rainfall records to be split into more homogeneous sub-samples, in term of meteorological genesis.

First results show how the combination of seasonal and WP sub-sampling strongly influences the identification of the asymptotic behaviour of rainfall probabilistic models. Furthermore, with this level of stratification, an asymptotic exponential behaviour of each sub-sample appears as a reasonable hypothesis. This first part is illustrated with two daily rainfall records from SE of France.

The distribution of the multi-exponential weather patterns (MEWP) is then defined as the composition, for a given season, of all WP sub-sample marginal distributions, weighted by the relative frequency of occurrence of each WP. This model is finally compared to Exponential and Generalized Pareto distributions, showing good features in terms of robustness and accuracy. These final statistical results are computed from a wide dataset of 478 rainfall chronicles spread on the southern half of France. All these data cover the 19532005 period.
\end{abstract}

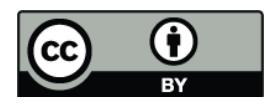

Correspondence to: F. Garavaglia (federico-externe.garavaglia@edf.fr)

\section{Introduction}

EDF (Électricité de France) design floods of dam spillways are now computed using a stochastic method named SCHADEX (Climatic-hydrological simulation of extreme floods) (Paquet et al., 2006). This method aims at estimating extreme flood quantiles by the combination of a rainfall probabilistic model and a continuous conceptual rainfall-runoff model (see Boughton and Droop, 2003 for a review). The purpose of this paper is to introduce the rainfall probabilistic model used in the SCHADEX method, based on a weather patterns sub-sampling. After introducing the weather patterns classification, we will first discuss the impact of this additional sub-sampling level on the identification of asymptotic behaviour of rainfall probabilistic models. We will finally present the formulation and the properties of this model and compare it with standard models.

In general the correct estimation of extreme rainfall quantiles is a critical stage in the estimation of extreme flood quantiles. In recent years, many approaches have been described in the hydrological literature to address this issue. Several solutions based on the extreme value theory use an asymptotic model to describe the stochastic behaviour of extreme value processes. Standard methodology for modelling extremes is based on the hypothesis of independence, stationarity and homogeneity. According to Coles et al. (2003), a false assumption of model homogeneity is one of the reasons that can lead to a wrong estimation of extreme events probabilities. The standard approaches based on extreme value theory use generalized extreme value (GEV) distribution or generalized Pareto (GP) distribution, and have to deal with the difficulty of locally estimating the shape parameter on

Published by Copernicus Publications on behalf of the European Geosciences Union. 
the basis of point data (Koutsoyiannis, 2004). Regional approaches, by gathering data at a spatial scale, allow to improve the robustness of parameter estimation. It consists either in refining the analysis to homogeneous climatic zones, in which the shape parameter is considered to be constant (Madsen et al., 1995; Ribatet et al., 2007; Pujol et al., 2008), or in using indirect methods, i.e. methods based on stochastic simulation of rainfall events, such as the SHYPRE method (Arnaud et al., 2007), in which the parameters are estimated using a regional approach (SHYREG method, Arnaud et al., 2006a).

In order to improve robustness without loosing accuracy in extreme rainfall estimation, we propose an alternative approach using a classification of atmospheric circulation patterns. These weather patterns (WP) provide a discriminating variable that is consistent with French climatology, and allow seasonal rainfall records to be split into more homogeneous sub-samples, in term of meteorological genesis. An exponential POT model is used to fit the distribution of each subsample. The distribution of the multi-exponential weather patterns (MEWP) is then defined as the composition, for a given season, of all WP sub-sample marginal distributions, weighted by the relative frequency of occurrence of each WP.

The weather pattern classification, so-called EDF 2006, is described in Sect. 2 below. The need for seasonal and weather pattern sub-sampling is explained in Sect. 3. In Sect. 4 we discuss the effect of sub-sampling on the identification of the asymptotic behaviour of rainfall probabilistic models. Section 3 and Sect. 4 are illustrated with the daily rainfall records from Lyon and St Etienne en Dévoluy (SE France). In Sect. 5 the MEWP rainfall probabilistic model is introduced. In order to assess the robustness and the accuracy of the proposed model, more global statistical results are computed from a wide dataset of 478 rainfall chronicles spread on the southern half of France (Fig. 1). All these data cover the 1953-2005 period.

\section{Weather patterns classification}

\subsection{Context}

The relationship between large-scale atmospheric circulation and precipitation events has been studied for a long time (see Yarnal et al., 2001; Boé et al., 2008; Martinez et al., 2008, for a review), especially over Western Europe, and it has been demonstrated that analysing synoptic situation can provide significant information on heavy rainfall events (Littmann, 2000). Various authors focused on the Mediterranean area (Romero et al., 1999; Littmann, 2000; Martinez et al., 2008).

From this point of view, a classification based on a limited number of typical but contrasted synoptic situations (or weather patterns) is a useful tool to link rainfall events with its generating processes. In this section, we identify the

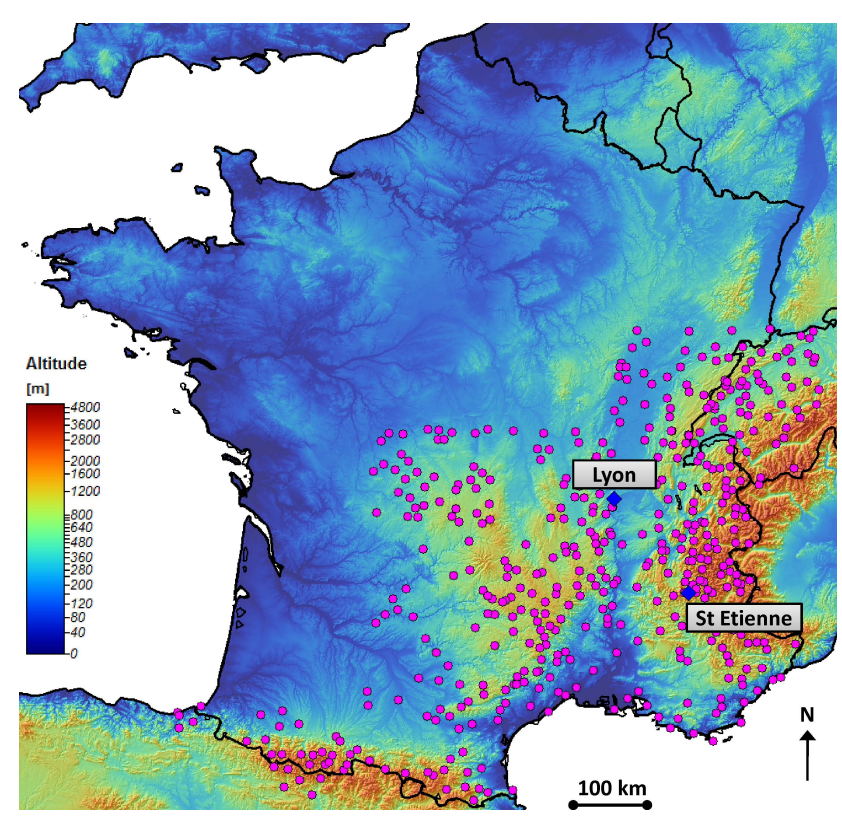

Fig. 1. Localisation of the 478 rain gauges used in this study (Lyon and St Etienne en Dévoluy rain gauges are highlighted).

weather patterns for France and the resulting classification of rainy days.

To define a daily synoptic situation over France and surrounding areas, we used a dataset that has already been optimised in previous works on quantitative precipitation forecast using the analogue method (Guilbaud et al., 1998; Obled et al., 2002):

- Geopotential height fields at 700 and $1000 \mathrm{hPa}$ pressure levels, at $0 \mathrm{~h}$ and $24 \mathrm{~h}$, defined on 110 grid points;

- Analysis centred on south-eastern France from $6.2^{\circ} \mathrm{W}$ to $12.9^{\circ} \mathrm{E}$, and from $38.0^{\circ} \mathrm{N}$ to $50.3^{\circ} \mathrm{N}$.

In this way, each day can be defined in the $\mathfrak{R}^{440}$ mathematical space of the geopotential fields concerned (four fields defined on 110 points).

\subsection{A "bottom-up" approach for the identification of weather patterns}

In our classification process, "bottom-up" should be understood as firstly identifying the centroids of classes using our variable of interest (i.e. rainfall), and secondly projecting them into the $\Re^{440}$ space of geopotential heights.

The whole classification process is summarized in Fig. 2, and consists of the following steps:

- STEP 1. To describe a daily precipitation field over France, 54 rainfall series for the period 1956-1996 are used. Among these records, 3086 days (21\%) with an 


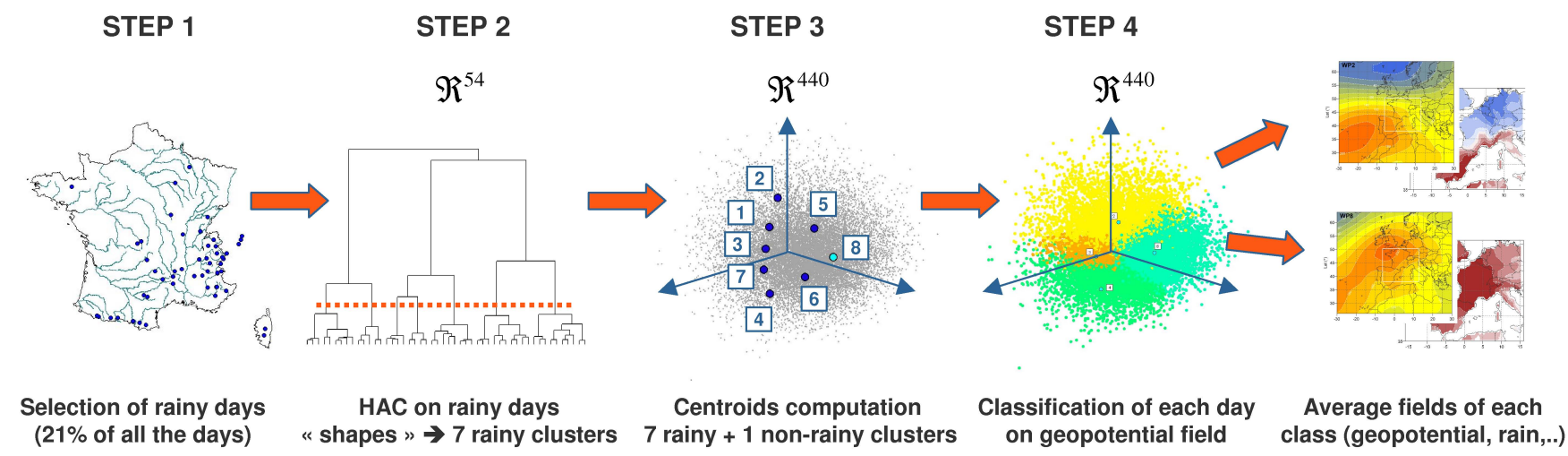

Fig. 2. WP classification flowchart.

average rain depth (computed on the 54 chronicles) exceeding $5 \mathrm{~mm}$, are considered as rainy days. We then normalize each local rain depth by the average precipitation of the day concerned, as a way of considering the "shape" of the rain field rather than its scale. Instead than using the how much does it rain information, we use the where does it rain information in our process.

- STEP 2. A Hierarchical Ascendant Classification (HAC) is then performed on this population of rainy day shapes, as defined in a $\mathfrak{R}^{54}$ space. The dendrogram of this HAC showed that seven rainy classes could be chosen, at this stage the remaining days (79\% of days) are combined in a non-rainy class.

- STEP 3. During this step the centres of gravity (or centroids) of the eight classes are calculated in the $\Re^{440}$ space of geopotential heights.

- STEP 4. Each day of the 1953-2005 period is attributed to the weather pattern (WP) whose centroid is the closest in the $\Re^{440}$, using the Teweles-Wobus score (Teweles and Wobus, 1954) as measure of proximity between synoptic situations. This led to changes for some days in the period 1956-1996 that were already classified by the HAC of rain, specially WP8 days (see below for the definition of WP8). Note that the Teweles-Wobus distance is used because we want to focus on atmospheric circulation, whatever the mean height of the geopotential fields (we could also have used other distances e.g. correlation between fields).

The obtained WPs are illustrated in Fig. 3a by their mean $1000 \mathrm{hPa}$ geopotential field at $0 \mathrm{~h}$. For pedagogical reasons, the fields are presented in logical order in terms of atmospheric circulations, i.e. 2-1-3-7-4-6-5 and 8 (see Fig. 2 Step 3). For each WP (except for WP8) an arrow indicates the atmospheric flow of low layers induced by the average synoptic fields. The size and the direction of the arrow are a qualitative indication of the strength and direction of the wind. Fig. $3 \mathrm{~b}$ shows the corresponding relative precipitation fields (ratio of WP mean to "all day" mean precipitation) over western Europe. For this purpose, we used a gridded version of the European Climate Assessment and Data (ECA\&D) of mean daily precipitation (Haylock et al., 2008). The grid resolution is $0.5 \times 0.5^{\circ}$ and the data cover the period 1953 to 2005 .

These patterns give a picture of the diversity of rainy synoptic situations over France. They were named in relation with the atmospheric circulation they favour. WP2 (Steady Oceanic), WP1 (Atlantic Wave) and WP3 (South-West Circulation) correspond to westerly oceanic circulations, WP1 being the most rainy pattern over the study area. WP7 (Central Depression) and WP4 (South Circulation) correspond to Mediterranean circulations, which bring heavy rains to south-eastern France. WP6 (East Return) also corresponds to a Mediterranean circulation, but rain is generally limited to the Italian border and eastern Pyrenees. WP5 (North East) is a continental circulation, and finally WP8 (Anticyclonic) shows no well-defined circulation, as expected for a nonrainy day. The occurrence statistics of the eight WPs are presented in Table 1. For the whole year, the most frequent WP is the Anticyclonic one (WP8), followed by the Steady Oceanic (WP2) and the South Circulation (WP4). However, these figures change with the season, for example WP2 is more frequent in winter, and WP8 in summer.

\subsection{Suitability of the proposed WP classification}

A weather pattern classification is a tool that cannot be separated from its object: a classification dedicated to wind or fog will obviously be significantly different from the one presented here. Furthermore, with not much contrasted mathematical objects like geopotential fields, clustering techniques are sensitive to initiation centers as well as to the number of classes. It is thus almost impossible to assert that a given classification "is the best", because for the same dataset, equivalent solutions can easily be obtained with slightly different options. More reasonably, a classification should be 

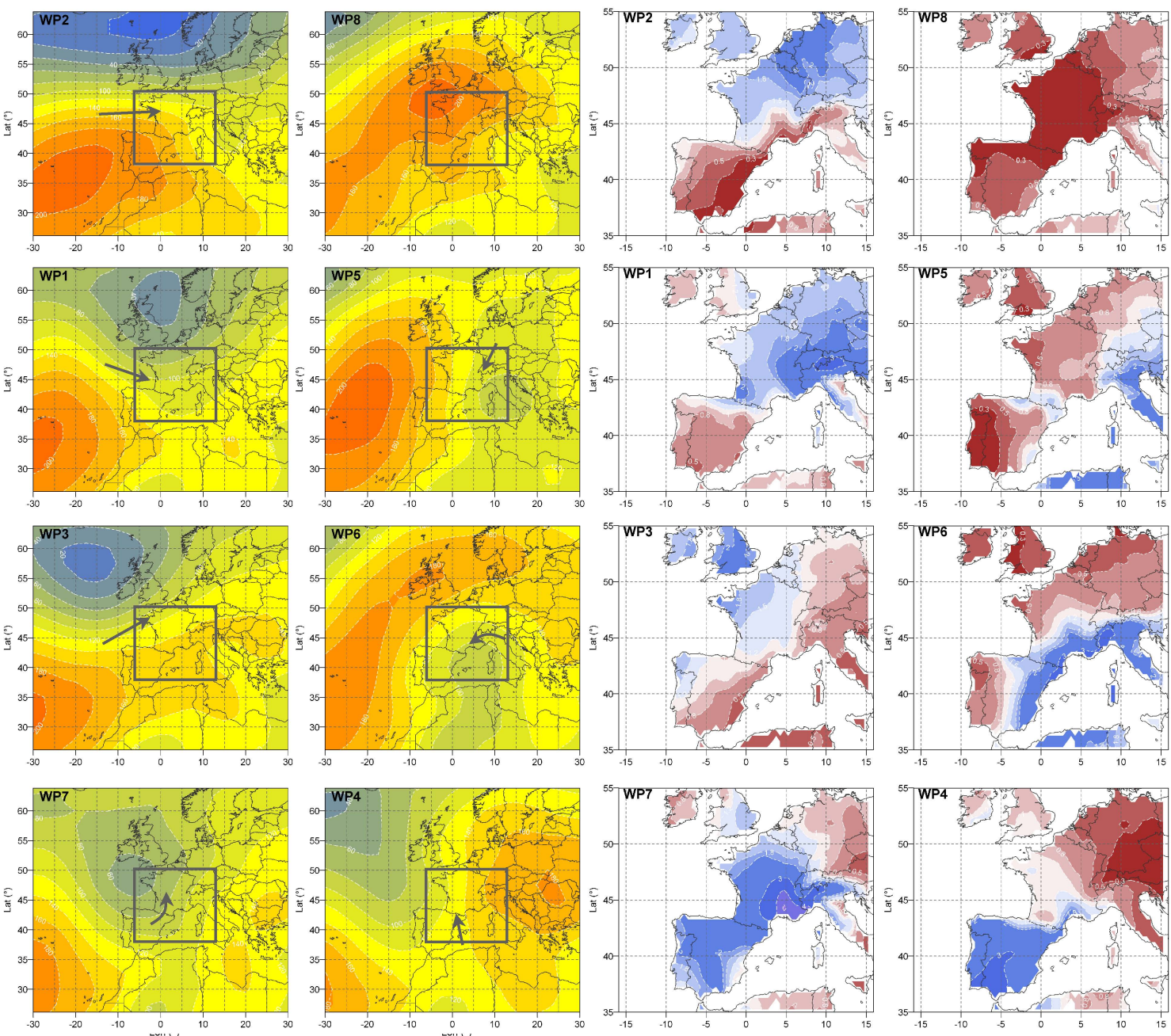

A
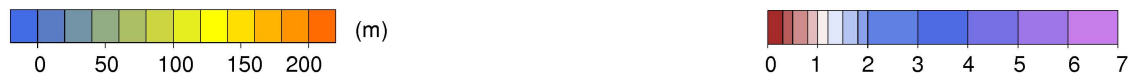

B

Fig. 3. Average geopotential height at $1000 \mathrm{hPa}$ of the eight WP (A) and the ratio of the mean WP to global mean precipitation (B). The frame highlights the area of interest (from $6.2^{\circ} \mathrm{W}$ to $12.9^{\circ} \mathrm{E}$, and from $38.0^{\circ} \mathrm{N}$ to $50.3^{\circ} \mathrm{N}$ ) and the arrows indicate the atmospheric flow of low layers.

Table 1. Yearly and seasonal statistics of occurrence for the eight WP (records for the period 1953-2005).

\begin{tabular}{lcccccc}
\hline Class & WP name & Year & Winter & Spring & Summer & Autumn \\
\hline WP1 & Atlantic Wave & $7 \%$ & $5 \%$ & $7 \%$ & $11 \%$ & $7 \%$ \\
WP2 & Steady Oceanic & $23 \%$ & $36 \%$ & $22 \%$ & $14 \%$ & $21 \%$ \\
WP3 & Southwest Circulation & $8 \%$ & $4 \%$ & $7 \%$ & $12 \%$ & $8 \%$ \\
WP4 & South Circulation & $18 \%$ & $19 \%$ & $18 \%$ & $10 \%$ & $23 \%$ \\
WP5 & Northeast Circulation & $7 \%$ & $7 \%$ & $8 \%$ & $6 \%$ & $6 \%$ \\
WP6 & East Return & $6 \%$ & $5 \%$ & $8 \%$ & $6 \%$ & $5 \%$ \\
WP7 & Central Depression & $3 \%$ & $2 \%$ & $4 \%$ & $3 \%$ & $4 \%$ \\
WP8 & Anticyclonic & $28 \%$ & $21 \%$ & $26 \%$ & $38 \%$ & $26 \%$ \\
\hline
\end{tabular}


Table 2. Comparison of the discriminating power of three classifications (average of statistics made on 54 rainfall records).

\begin{tabular}{ccccc}
\hline Classification & Region & Number of classes & Cramer Coefficient & Intra deviation score \\
\hline Hess and Brezowsky (1952) & Central Europe & 30 & 0.336 & 0.916 \\
Boé (2007) & France & 38 & 0.429 & 0.856 \\
EDF 2006 & France & 8 & 0.427 & 0.878 \\
EDF 2006 (seasonal) & France & $8 \mathrm{x} 4$ & 0.453 & 0.856 \\
\hline
\end{tabular}

evaluated on its ability to propose a reasonable typology of the phenomenon concerned.

Two other available classifications were evaluated and compared to the one proposed here: the well-known HessBrezowsky classification (Hess and Brezowsky, 1952), because it is often used for comparison, and another French classification (Boé, 2007), which is also used for precipitation analysis. The latter classification in fact comprises four classifications of 8-10 classes, one for each season (DJF, MAM, JJA, SON). The discriminating power of the three classifications was checked for rain/no rain occurrence, using appropriate criteria like the Cramer test (Bardossy et al., 1995). This coefficient ranges between 0 (no dependence between the classification and the rain/no rain occurrence) and 1 (absolute dependence). Another criterion is also computed to check how the classification minimizes deviation within classes. The chosen criterion is the ratio of intra classes deviation to total deviation. This coefficient ranges between 1 (equal deviation within classes than the total population) and 0 (no deviation within classes : each class contains the same numeric value). These criteria are first computed on each of our 54 rainfall chronicles on the period 1953-1998 and then averaged to obtain a single value. The results of the comparison are presented in Table 2, and show that the present classification based on the eight WPs has good discriminating power for the rain occurrence and value.

In addition, the corresponding average rain fields are contrasted (Fig. 3b). In our opinion, one of the major advantages of this classification is that it remains applicable throughout the year, enabling flexible use. For example, in a recent study by Gottardi (2009), this classification was used to interpolate daily precipitation fields over French mountainous regions. It is now time to evaluate its interest for heavy rainfall distribution.

\section{Extreme value theory and sampling techniques}

\subsection{Sampling techniques for extreme values}

The extreme value theory is based on the fundamental hypothesis that the random variable realizations (daily rainfall in our study) are independent and identically distributed (i.i.d). Two standard sampling techniques are used to build samples coming closer to these hypotheses:
- Block Maximum (BM). The maximum values within blocks of equal length of data are selected. The choice of block size can be critical as too small blocks can lead to bias and too large blocks generate too few block maxima, thus giving a large estimation variance (Coles, 2001). Usually the one-year block is used for daily discharges or rainfall data, leading to the annual maxima (AM). According to Coles et al. (2003), asymptotic consideration suggest that the distribution of AM should be approximately a member of the generalized extreme value (GEV) distribution.

- Peaks over threshold (POT). All the events exceeding a given threshold are selected (see Lang et al., 1999; Rosbierg and Madsen, 2004, for a review). Once again according to Coles (2001), such a sample may be regarded as independent realizations of a random variable whose distribution can be approximated by a member of generalized Pareto distribution.

Always according to Coles et al. (2003), if daily series are available, POT sampling is better that AM sampling, because additional information on several large events that occur during the same year is taken into account.

To ensure independence of POT values, an additional criterion based on a minimum time period between two successive events is usually applied. In this paper, we begin to introduce a new variable, called the "central rainfall", which is, at a daily time step, rainfall exceeding $1 \mathrm{~mm}$ and greater than the quantity of rain on the preceding and following day. This CR sampling is closely linked to the rainfall-runoff simulation process part of the SCHADEX method. The independence of this kind of re-sampled rainfall time series has been checked by computing the first order lag autocorrelation coefficients for the whole dataset (map on Fig. 1). The median autocorrelation coefficient is 0 for AM sampling method, 0.07 for CR sampling method and 0.23 for daily time-series. We therefore selected POT values of "central rainfalls". In the Lyon records, the so-called "central rainfalls" represent about $17 \%$ of all daily rainfall (63\% of the days being nonrainy days, and the $20 \%$ remaining days thus having less rainfall than the preceding or following days).

However, the "identically distributed" quality of such samples is somewhat questionable: the main feature shared by the selected observations is their status of being the yearly maximum, or greater than a specific threshold. This can be 
illustrated by considering daily discharges of small mountain catchments where high values are commonly observed either in spring or autumn. In this case, two populations linked to very different hydrological processes (snowmelt or heavy rain runoff floods) are mixed by BM or POT sampling (Hirschboeck et al., 1987; Petrow et al., 2007), making the "identically distributed" hypothesis harder to ensure, and consequently the use of extreme value statistical theory more questionable.

Therefore, two complementary sub-sampling techniques for rainfall records are introduced here to more closely approach the i.i.d. hypothesis.

\subsection{Seasonal sub-sampling}

In most places in the world and in a wide range of climates, rainfall displays strong seasonal variability. At a given location, the frequency and intensity of rainfall is driven by the meteorological situation, whose genesis is strongly influenced by large scale seasonal factors, for example variation in solar input (incidence of sunlight, day length), sea surface temperatures, the position of long lasting high or low pressure centers etc. The factors that cause heavy rainfall events are numerous, various and complex, and they interact at different scales, but their seasonal variation pattern has a true climatological consistency. This is common sense in strong bipolar precipitation regimes (like monsoon), but is also true in temperate climates with more mixed influences. For example, heavy rains hitting the French, Spanish and Italian regions surrounding the Mediterranean Sea most likely occur during fall (September to November). This kind of pattern must be taken into account by appropriate seasonal sampling to produce more homogeneous sub-populations for heavy rainfall analysis (Lang and Desurosne, 1994; Djerboua and Lang, 2007). In extreme rainfall studies for France, we usually consider two to four non-overlapping seasons.

Fig. 4 is a box plot of annual daily rainfall maxima for each month at Lyon and St Etienne en Dévoluy. The seasonal pattern is rather common for daily rainfall in southern France, with the highest quantiles ("season-at-risk") occurring between September and November (as shown for St Etienne en Dévoluy). For Lyon, this "season-at-risk" is more likely June to November.

\subsection{Weather Pattern based sub-sampling}

As indicated in Sect. 2.1, in Europe, the links between atmospheric circulation patterns and heavy rainfall events have been widely studied in various locations. The analysis domain on which the classification is built is generally wide (several degrees of latitude and longitude), and thus has a regional sense. A discrimination of rainfall records based on such a classification is one way to gather observations according to similar generating meteorological processes, and hence progress toward to the homogeneity of sub-samples.
One application was described by Ramos et al. (2001) for the 30' rainfall in Marseilles (France), showing two distinct asymptotic behaviours depending on the presence of a mesoscale convective system. This approach can also provide additional information about extreme rainfall events, thus enhancing probabilistic analysis (Klemeŝ, 1993). Figure 5 is a box-plot of annual maxima for each weather pattern for Lyon and St Etienne en Dévoluy. The WP4 (South Circulation), WP7 (Central Depression), and to a lesser extent WP1 (Atlantic Wave), clearly have higher quantiles than the other weather patterns. We will now show how to integrate these sub-samplings into rainfall probabilistic models.

\section{Taking into account seasonal and weather pattern sub-sampling}

\subsection{Global formulation}

Let $Y$ represents the hydrologic variable of interest such as daily rainfall (or central rainfall, see above). Let us now consider a range of seasons $i=1, \ldots, S$, where $S$ is the number of seasons that allows appropriate seasonal division of the local precipitation regime ( $S$ equal to 2 or 4 generally in France).

Let us also consider a range of weather patterns $j=1, \ldots$, NWP, where NWP is the number of weather patterns that provides a robust discrimination of the meteorological situations of the study region (for France, NWP equal to 8 for the classification presented in Sect. 2).

To build sub-samples based on seasons and weather patterns, the hydrologic variable $Y$ is partitioned into $S$. NWP variables, $Y_{\mathrm{NWP}=j}^{S=i}$, with respect to seasons and weather patterns, as follows:

$Y=\bigcup_{i=1}^{S} Y^{i}$ and $Y^{i}=\bigcup_{j=1}^{\mathrm{NWP}} Y_{j}^{i}$

As mentioned before, asymptotic behaviour of POT values of a daily rainfall sub-sample of season $i$ and WP $j$, may be approached by a GP distribution, which takes the form:

$F_{j}^{i}(z)=\operatorname{Pr}\left[Z_{j}^{i}=Y_{j}^{i}-u_{j}^{i}<z\right]=1-\left(1+\xi_{j}^{i} \frac{z}{\lambda_{j}^{i}}\right)^{-\frac{1}{\xi_{j}^{i}}}$

with a parameter space $\left\{\left(\lambda_{j}^{i}, \xi_{j}^{i}\right): \lambda_{j}^{i}>0, \xi_{j}^{i} \in \Re\right\}$, and a threshold $u_{j}^{i}$.

As the set of seasonal POT values across all WP is the union of the POT values within each WP, the seasonal rainfall distribution is computed from a mixture distribution of GP distribution for each WP. This seasonal distribution takes the form:

$F^{i}(z)=\sum_{j=1}^{\mathrm{NWP}} F_{j}^{i}(z) \cdot p_{j}^{i}$ 

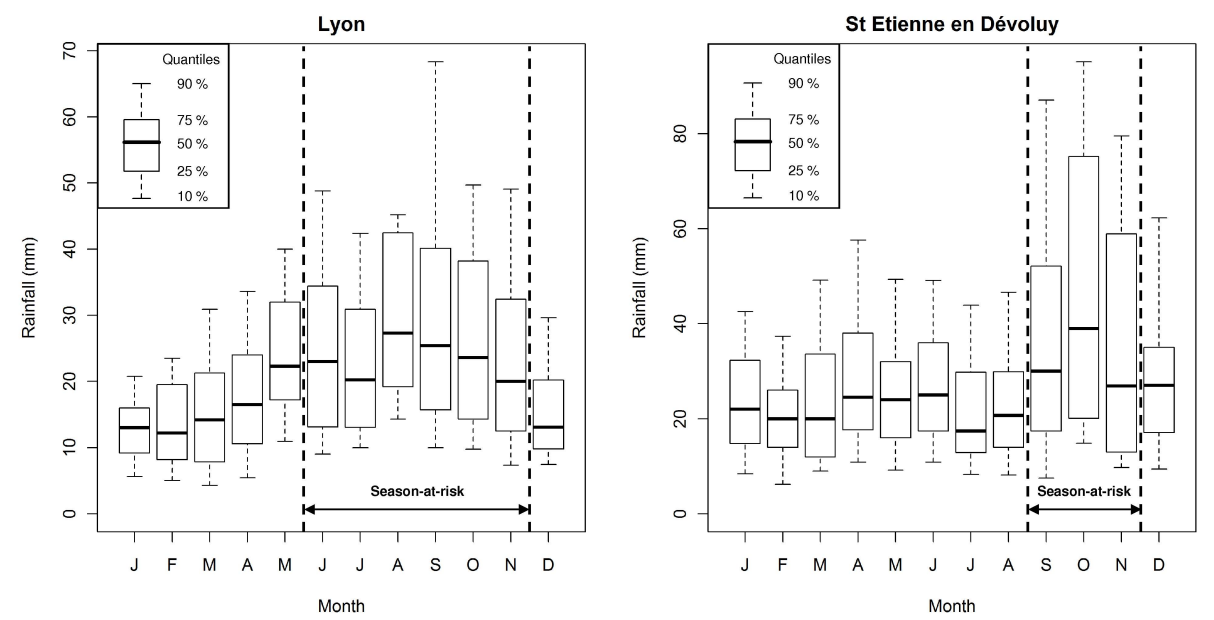

Fig. 4. Box plot of the annual maxima for each month at Lyon rain gauge (left) and St Etienne en Dévoluy (right) (records for the period 1953-2005). Dashed lines and double arrow highlight the "season-at-risk" (season of occurrence of highest rainfall quantiles) at Lyon (June to November) and St Etienne en Dévoluy (September to November).
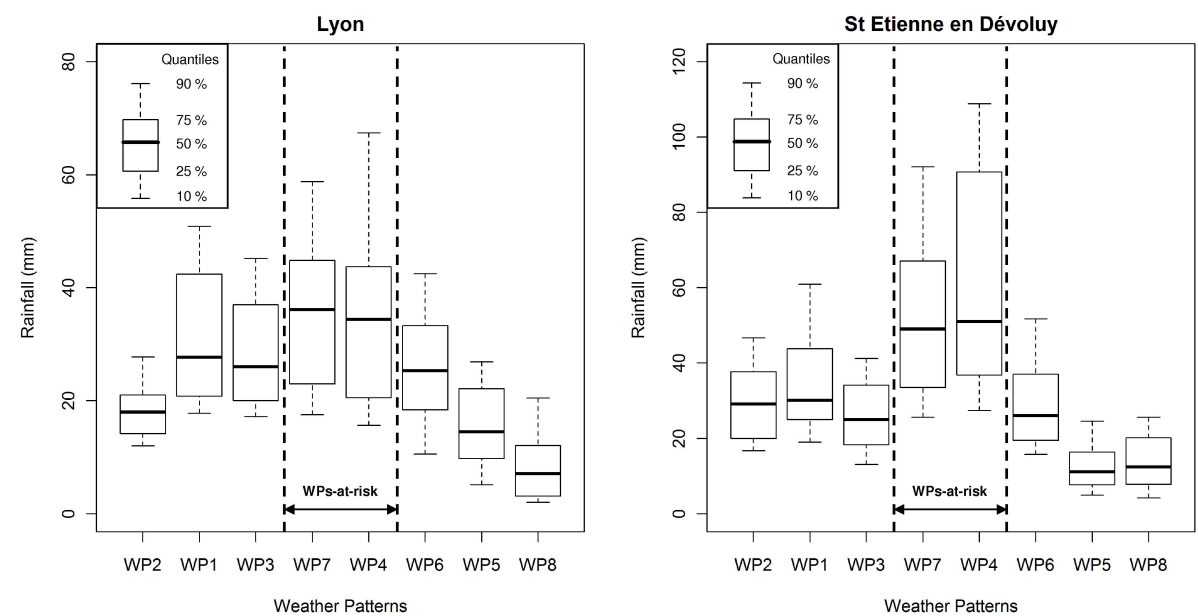

Fig. 5. Box plot of the annual maxima for each weather pattern at Lyon rain gauge (left) and St Etienne en Dévouly (right) (records for the period 1953-2005). Dashed lines and double arrow highlight the "WPs-at-risk" (WP associated to highest rainfall quantiles): WP 7 and WP 4.

where weight $p_{j}^{i}$ is the relative occurrence of each WP within season $i$. The global distribution is therefore computed from a mixture distribution of each seasonal distribution, which takes the form:

$F(z)=\sum_{i=1}^{S} F^{i}(z) \cdot p^{i}$

where weight $p^{i}$ is the relative occurrence of each season that is equal to the ratio of the number of events in the season to the total number of events.

\subsection{Relation between sub-sampling and asymptotic behaviour}

An appropriate tool for the threshold selection is the Mean Residual Life (MRL) plot, expressed as follow :

$\left[\left(u, \frac{1}{n_{u}} \sum_{i=1}^{n_{u}}\left(x_{i}-u\right)\right): u<x_{\max }\right]$

where $x_{1}, \ldots, x_{n_{u}}$ consist of the $n_{u}$ observations that exceed threshold $u$, and $x_{\max }$ is the largest of the $x_{i}$. According to Coles (2001), above a threshold $u_{0}$ at which the GP distribution provides a valid approximation to the excess distribution, the MRL plot should be approximately linear in $u$. 


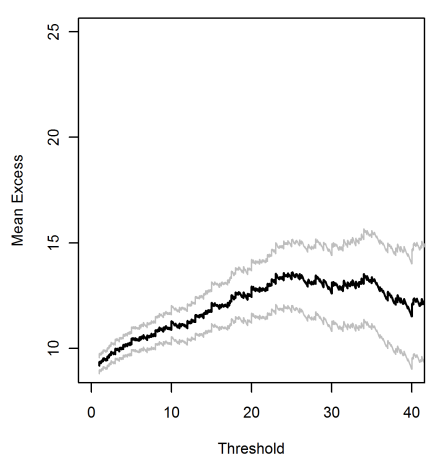

D

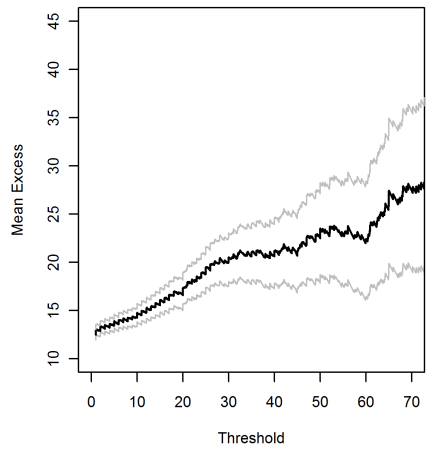

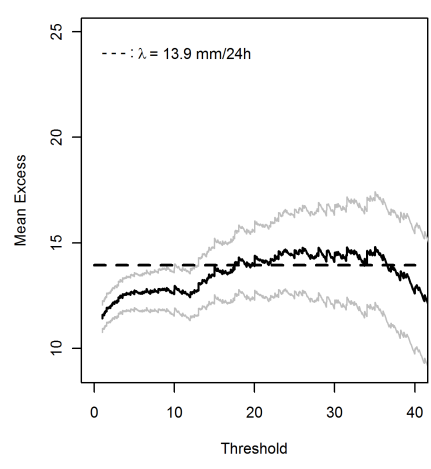

E

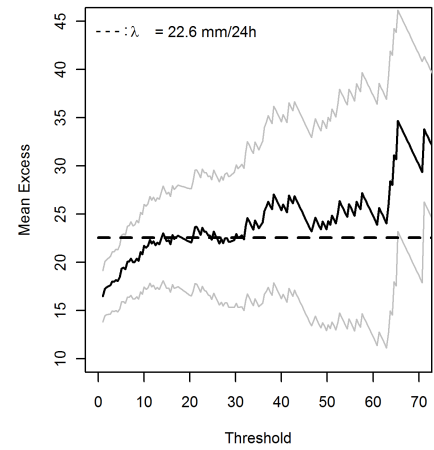

C

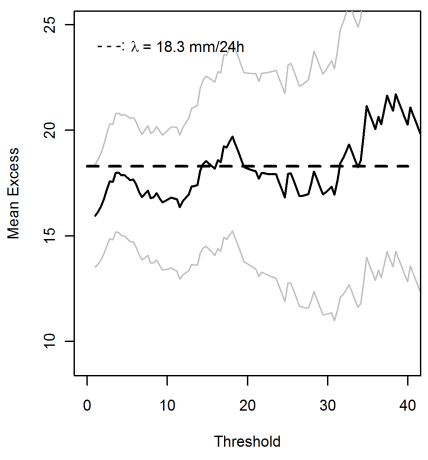

$\mathrm{F}$

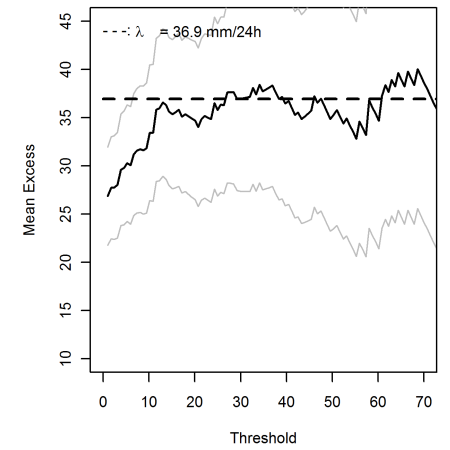

Fig. 6. MRL plot for all year (A and D), "season-at-risk" (B and $\mathbf{E})$ and WP 4 days within "season-at-risk" (C and $\mathbf{F})$ at Lyon rain gauge (A, B and C) and St Etienne en Dévoluy (D, E and F). Gray lines represent the 95\% confidence interval. The dashed lines highlight the fitted value of the scale parameter according to an exponential model.

More specifically, the mean excess above the threshold $u_{0}$ should be constant, equal to the scale parameter $\lambda$ for the case of exponential distribution $(\xi=0)$, and should increase linearly with the threshold value for the Pareto distribution $(\xi>0)$ (Shanbhag 1970). Confidence intervals, based on the hypothesis of normality of the sample means, can be added to the plot.

The graphical interpretation of an MRL plot may appear as subjective. However, in our study, it has been used to illustrate how the vision of the asymptotic behaviour of a given population may be dependent of the chosen sampling level (global, season, season and WP). Figure 6 shows MRL plots for the whole year, the "season-at-risk", and for the WP4 days within the "season-at-risk", at Lyon and St Etienne en Dévoluy rain gauges. Considering Fig. 6d (St Etienne en Dévoluy, global sample), a reasonable interpretation of the increasing linear trend of the MRL plot may be a Pareto asymptotic underlying behaviour. This is more questionable for the Fig. 6e (St Etienne en Dévoluy, "season-atrisk"), where asymptotic exponential behaviour could be a possible interpretation $(22.6 \mathrm{~mm} / 24 \mathrm{~h}$ scale parameter). The exponential hypothesis $(36.9 \mathrm{~mm} / 24 \mathrm{~h}$ scale parameter) becomes a more natural choice for the Fig. 6f (St Etienne en Dévoluy, WP4 days within the "season-at-risk"). Similar conclusions can be drawn for the example of Lyon (Fig. 6a to 6c), but with an asymptotic exponential behaviour almost noticeable on the whole year MRL plot above $25 \mathrm{~mm}$ threshold (Fig. 6a).

The MRL plot is supposed to help to determine the asymptotic behaviour of the underlying distribution, but we see how far the final diagnostic can depend on the chosen subsampling. In other words, the asymptotic behaviour might be exponential, but a standard sub-sampling (e.g. records from whole year or whole season) might completely mask it. Furthermore, under the hypothesis of an exponential asymptotic behaviour, a standard sub-sampling might lead to an underestimation of the scale parameter: Lyon scale parameter rising from $13.9 \mathrm{~mm} / 24 \mathrm{~h}$ ("season-at-risk") to $18.3 \mathrm{~mm} / 24 \mathrm{~h}$ (WP4 in "season-at-risk"), St Etienne en Dévoluy scale parameter from $22.6 \mathrm{~mm} / 24 \mathrm{~h}$ to $36.9 \mathrm{~mm} / 24 \mathrm{~h}$. Figure 7 shows additional MRL plots for Lyon WP7, WP6 and WP1 sub-samples (within "season-at-risk") with a more apparent asymptotic exponential behaviour.

From now on, our hypothesis will be that the asymptotic behaviour of each WP sub-sample within season is exponential. This hypothesis will be presented and tested in the following section. 

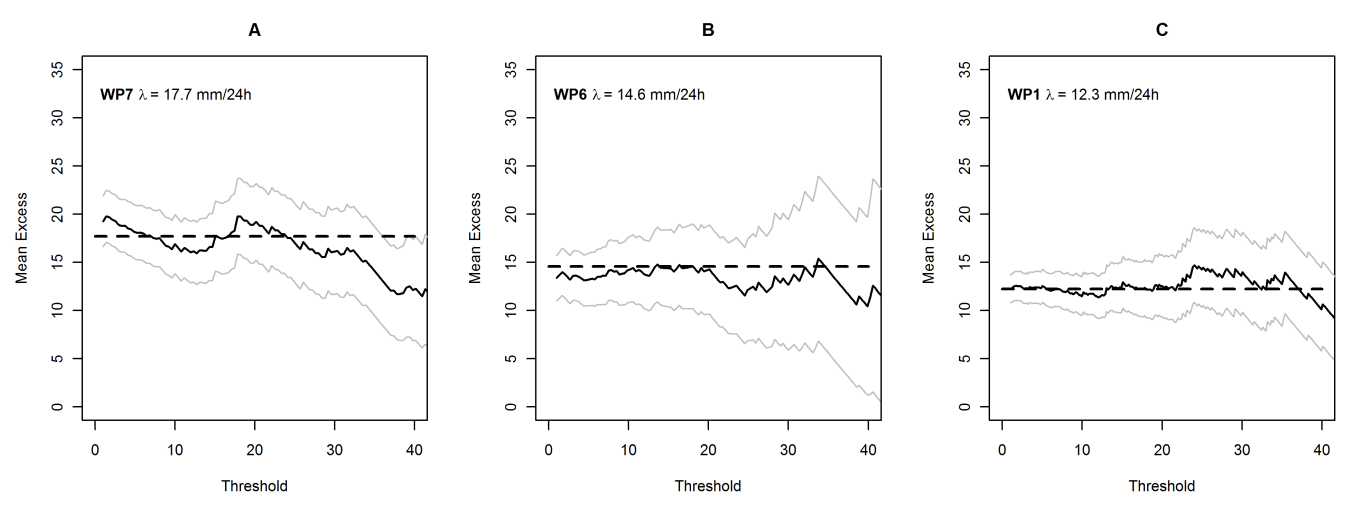

Fig. 7. MRL plot for WP7 (A), WP6 (B) and WP1 (C) days in the season from June to November ("season-at-risk") at Lyon rain gauge. Gray lines represent the $95 \%$ confidence interval. The dashed line highlights the fitted value of the scale parameter according to an exponential model.

\section{Multi-exponential weather pattern distribution}

\subsection{Model formulation}

Considering that the shape parameter $\xi_{j}^{i}$ is equal to zero, the seasonal distribution given in Eq. 3 takes the form:

$F^{i}(z)=\sum_{j=1}^{N W P} F_{j}^{i}(z) \cdot p_{j}^{i}=\sum_{j=1}^{N W P}\left(1-\exp \left(-\frac{z}{\lambda_{j}^{i}}\right)\right) \cdot p_{j}^{i}$

This seasonal distribution is then named multi-exponential weather pattern (MEWP) distribution. To provide a continuous probabilistic description of the whole range of observed rainfall, the CDF of each sub-sample is extended below its threshold $u_{j}^{i}$ by a linear interpolation of empirical quantiles. Otherwise, the MEWP distribution would only be defined above the greatest threshold of all sub-samples.

In practice, selecting a threshold level $u_{j}^{i}$ is not an easy task. In order to avoid compromising the asymptotic characteristic of the fitted values - threshold too low - and to avoid enlarging the variance of the estimators - threshold too high -, $u_{j}^{i}$ was chosen equal to the $70 \%$ empirical quantile of each WP sub-sample. This choice of threshold was checked on MRL plots. It proved to be a good compromise for the dataset presented in Fig. 1.

The confidence intervals are computed using the bootstrap non-parametric method (Efron , 1979). It consists in a random extraction with replace of values from the actual sample (WP sampling), in order to produce new samples (Bootstrap samples) of the same dimension of actual one. For every Bootstrap samples, the quantiles of given frequency $f, q_{f}$, are determined via the probabilistic model considered. If $q_{B, \alpha / 2}, q_{B, 1-\alpha / 2}$ are the empirical quantiles of frequency $\alpha / 2$ and $1-\alpha / 2$ of the empirical distribution $q_{f}$, the confidence interval at $1-\alpha$ level is equal to $\left[q_{B, \alpha / 2}, q_{B, 1-\alpha / 2}\right]$ around the quantile. In order to take into account the variability of the occurrence of each WP in the computation of bootstrap interval of confidence, we modeled this occurrence with a
Poisson law. So for every bootstrap simulation, we extract randomly from a Poisson law the occurrence of the WPs.

Table 3 shows the scale parameter $\lambda_{j}^{i}$, the threshold $u_{j}^{i}$ (corresponding to the $70 \%$ empirical quantile) and the weight $p_{j}^{i}$ of each WP within the annual and the two seasonal MEWP distributions (December to May, June to November) for the Lyon rain gauge. The last line gives the weight $p^{i}$ of each season used to compute the annual MEWP distribution. These results reveal significant variability of the scale parameter in relation with the WP and the season. We consider this variability as an indication of the suitability of WP sampling: inappropriate sub-sampling would have produced randomly parsed samples of the whole record, with a rather uniform scale parameter for each sub-sample. Figure 8 illustrates the eight WP exponential distributions fitted on the Lyon rainfall records within the season Jun-Nov and the period 1953-2005. The x-axis of these graphs shows the return level, $T(z)$, expressed in years, obtained from the density function $F(z)$, through the following expression:

$T(z)=\frac{1}{1-F(z)^{\frac{n}{N}}}$

where $n$ is the number of elements of the sub-sample concerned (e.g. daily rainfall in autumn and WP1) and $N$ is the number of years of the data (i.e. 53 for the period 19532005). We can now define the "WP-at-risk" within a given season as the WP associated with the greatest scale parameter (numbers in bold in Table 3). For the season 1 (December to May), it is WP7 ( $\lambda_{7}$ equal to $10.2 \mathrm{~mm} / 24 \mathrm{~h}$ ), whereas in season 2 (the "season-at-risk", from June to November) it is WP4 ( $\lambda_{4}$ equal to $18.3 \mathrm{~mm} / 24 \mathrm{~h}$ ), showing seasonal variations. This result is fully consistent with the climatological characteristics of the Lyon area, with Mediterranean circulations causing the heaviest rainfall events, especially in autumn. The last columns of Table 3 illustrate the relevancy of a seasonal sub-sampling; for the whole year (annual distribution) scale parameters of each WP still show a strong 
Table 3. Scale parameter $\lambda_{j}^{i}$, threshold $u_{j}^{i}$, weight $p_{j}^{i}$ for each weather pattern of the two seasonal MEWP distributions (season 1 from December to May and season 2 from June to November) for Lyon. Last columns detail the annual MEWP distribution (without seasonal sub-sampling). The weights $p^{i}$ refer to the weights used to compute the global MEWP distribution, if season sampling is used.

\begin{tabular}{|c|c|c|c|c|c|c|c|c|c|}
\hline & \multicolumn{3}{|c|}{ Season 1 (Dec-May) } & \multicolumn{3}{|c|}{ Season 2 (Jun-Nov) } & \multicolumn{3}{|c|}{ Annual (without season) } \\
\hline & $\begin{array}{c}\lambda_{j}^{i} \\
(\mathrm{~mm} / 24 \mathrm{~h})\end{array}$ & $\begin{array}{c}u_{j}^{i} \\
(\mathrm{~mm})\end{array}$ & $p_{j}^{i}$ & $\begin{array}{c}\lambda_{j}^{i} \\
(\mathrm{~mm} / 24 \mathrm{~h})\end{array}$ & $\begin{array}{c}u_{j}^{i} \\
(\mathrm{~mm})\end{array}$ & $p_{j}^{i}$ & $\begin{array}{c}\lambda_{j}^{i} \\
(\mathrm{~mm} / 24 \mathrm{~h})\end{array}$ & $\begin{array}{c}u_{j}^{i} \\
(\mathrm{~mm})\end{array}$ & $p_{j}^{i}$ \\
\hline WP1 & 9.4 & 10.1 & $13 \%$ & 12.3 & 15 & $18 \%$ & 11.1 & 13 & $15 \%$ \\
\hline WP2 & 4.4 & 7 & $38 \%$ & 5.5 & 7.8 & $21 \%$ & 4.8 & 7.3 & $30 \%$ \\
\hline WP3 & 9.2 & 9.7 & $8 \%$ & 10.7 & 16.4 & $16 \%$ & 10.6 & 14.2 & $12 \%$ \\
\hline WP4 & 8.8 & 13 & $15 \%$ & 18.3 & 19.5 & $13 \%$ & 14.3 & 15.3 & $14 \%$ \\
\hline WP5 & 4.9 & 7.1 & $8 \%$ & 8.3 & 12.1 & $8 \%$ & 8.2 & 8.3 & $8 \%$ \\
\hline WP6 & 9.9 & 11.8 & $6 \%$ & 14.6 & 16.5 & $8 \%$ & 12.2 & 15.1 & $7 \%$ \\
\hline WP7 & 10.2 & 17 & $8 \%$ & 17.7 & 23.9 & $10 \%$ & 15.6 & 19.7 & $9 \%$ \\
\hline WP8 & 2.6 & 3.3 & $4 \%$ & 8.6 & 7.8 & $6 \%$ & 7.4 & 5 & $5 \%$ \\
\hline$p^{i}$ & \multicolumn{3}{|c|}{$50 \%$} & \multicolumn{3}{|c|}{$50 \%$} & \multicolumn{3}{|c|}{$100 \%$} \\
\hline
\end{tabular}

variability, but at a lower level. Choice of seasons may appear as subjective but remains a mandatory step accounting for additional meteorological factors. For instance, concerning Mediterranean regions, the seasonal variation of heavy precipitations of a given WP is partly linked to the evolution of the Mediterranean Sea surface temperature. The eight WP exponential distributions illustrated in Fig. 8 are combined in a seasonal MEWP distribution (Fig. 9a) using the weight $p_{j}^{i}$ given in Table 3. Similarly the two seasonal MEWP distributions are combined in the global MEWP distribution illustrated in Fig. 9b, according to the seasonal weight $p^{i}$ given in Table 3.

\subsection{Model properties}

Two important features of this model should be underlined:

- A significant bend of the CDF for low to moderate return times can be represented, meaning non-exponential behaviour of distributions in the range of observable frequencies can be accounted for;

- For high and extreme quantiles (currently over 50 years of return period), the asymptotic behaviour becomes exponential, and is fully parameterized by the scale parameter and the relative frequency $p_{j}^{i}$ of the "WP-atrisk" and the "season-at-risk".

However, the high flexibility of a probabilistic model, i.e. its ability to fit the largest observed values, often has the serious drawback of lacking robustness for estimations of extreme quantiles. Figure 10 illustrates the robustness of the proposed probabilistic model. The MEWP distribution was compared with the Exponential (EXP) and GP distribution for the Lyon record. Both models were fitted locally (using maximum likelihood criterion) on two samples: the observations of Jun-Nov season for the period 1953-2005, with and without the maximum observed event $(101 \mathrm{~mm}$ rainfall in $24 \mathrm{~h}$ on 30 September 1958).

The estimate of the 1000-year return level for daily rainfall is $120 \mathrm{~mm}$ with the GP distribution fitted on the complete record, and $104 \mathrm{~mm}$ with the GP distribution fitted without the observed maximum ( $11 \%$ less). For EXP distribution, these values are respectively $142 \mathrm{~mm}$ and $139 \mathrm{~mm} \mathrm{(2 \%}$ less). For the MEWP distribution, these values are respectively $160 \mathrm{~mm}$ and $159 \mathrm{~mm}$ (1\% less), with almost identical distributions on Fig. 10. This test has been carried out on a wide dataset of 478 rain gauges located in the Alps, Pyrenees and Central Massif (Fig. 1). Three probabilistic models (EXP, MEWP and GP distribution) have been fitted on the "season-at-risk" records of the 1953-2005 period, with and without the observed maximum. For each model, the same threshold has been used, corresponding to the one conditioning the asymptotic value of the MEWP distribution (i.e. the $70 \%$ empirical quantile of the "WP-at-risk" sub-sample). For two return levels (100 and 1000 years) we compute the relative deviation between the two estimations (with and without the observed maximum) of each model. The Fig. 11 shows the box plot of this relative deviation for the 478 rain gauges. For 1000-year return level, the median of this relative deviation is $17 \%$ for GP distribution, $4 \%$ for exponential distribution and 3\% for MEWP distribution. For such a local fit of models, the MEWP and EXP distributions appear as more robust than the GP distribution for the estimation of extreme rainfall events. This is logically a consequence of a unique parameter driving the asymptotic behaviour of both EXP and MEWP distributions. Concerning the MEWP distribution, the number of underlying parameters (within a season, a scale parameter for each 8 WP sample and eight WP relative frequency) may be viewed a priori as a restriction for robustness. The presented test shows that this is not the case.

This robustness test has to be completed by an accuracy test. Dealing with extremes values, finding a relevant 

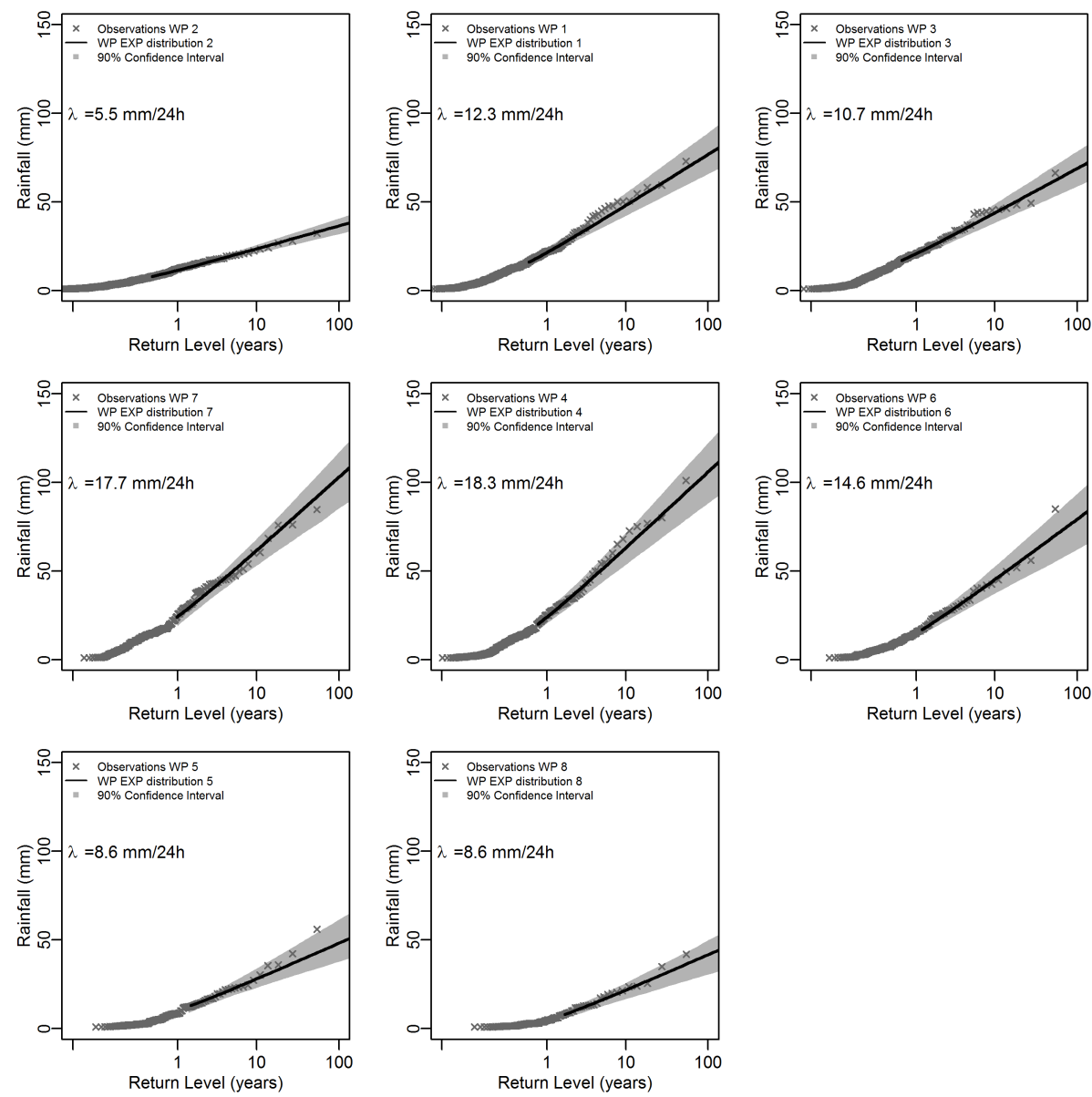

Fig. 8. Exponential distributions of the eight WP sub-samples for Lyon rain gauges (data from the period 1953-2005; "season-at-risk" (June to November)). The gray zone highlights the $90 \%$ confidence intervals.

accuracy test is not an easy task. Arnaud et al. (2006b) proposed a simple test, called "regional test", assuming the spatial independence of highest quantiles. If $n_{1}$ years of records are available for $n_{2}$ rain gauges, the local estimation of the 1000 years return level by a correct probabilistic model, should be exceeded around $\left(n_{1} \times n_{2}\right) / 1000$ times on the whole dataset. This test is weakened by the spatial independence hypothesis, but it remains useful for model comparison. It has been used on the 478 rain gauges dataset, for the 1953-2005 records on the "season-at-risk" (i.e. 25334 year $\times$ station), for the EXP, MEWP and GP models. Results are shown in Table 4 for the 1000 year return level. Theoretically, the 0.999 quantile should be exceeded 25 times in this dataset. The EXP distribution underestimates it (60 exceedances in the dataset), the GPD model overestimates it (7 exceedances), and the MEWP is closer to the theoretical value (32 exceedances). The MEWP distribution provides higher estimation of extreme rainfall, compared to the EXP distribution, correcting appropriately its notorious underestimating bias.
Table 4. Number of exceedances of the local millennial quantile for the three models (EXP, MEWP, GPD) computed on the 478 rain gauges. Left columns shows the "theoretical" number of exceedances expected.

\begin{tabular}{cccc}
\hline \multicolumn{4}{c}{$f=0.999$} \\
\hline "Theoretical" & EXP & MEWP & GPD \\
25 & 60 & 32 & 7 \\
\hline
\end{tabular}

\section{Conclusions}

The main features of the proposed MEWP approach can be summarized as follows:

- Construction of a rain-oriented weather pattern classification to approach the meteorological genesis of heavy rains, over an area of mixed climatological influences;

- Discrimination of a rainfall record based on this classification; 
A

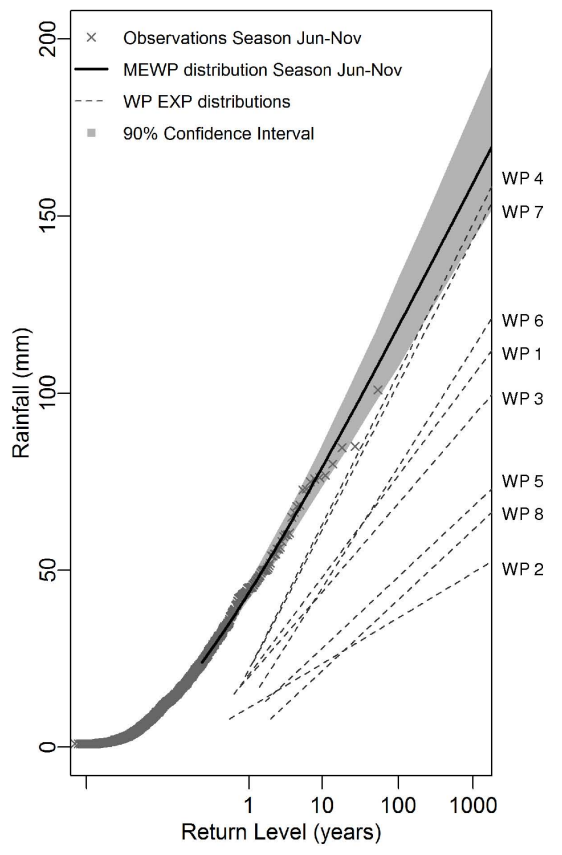

B

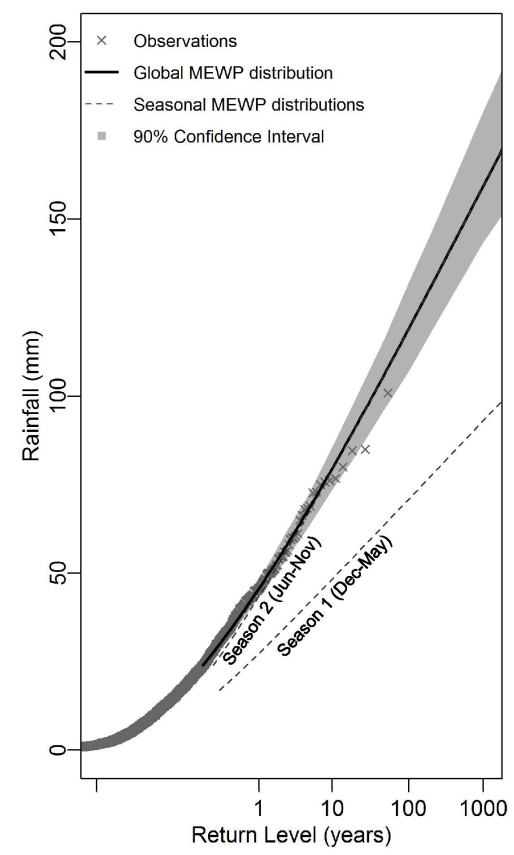

Fig. 9. MEWP distribution of the "season-at-risk" (June to November) (A) and global MEWP distribution (B) for the Lyon rain gauge (data from the period 1953-2005). The gray zone highlights the $90 \%$ confidence intervals.

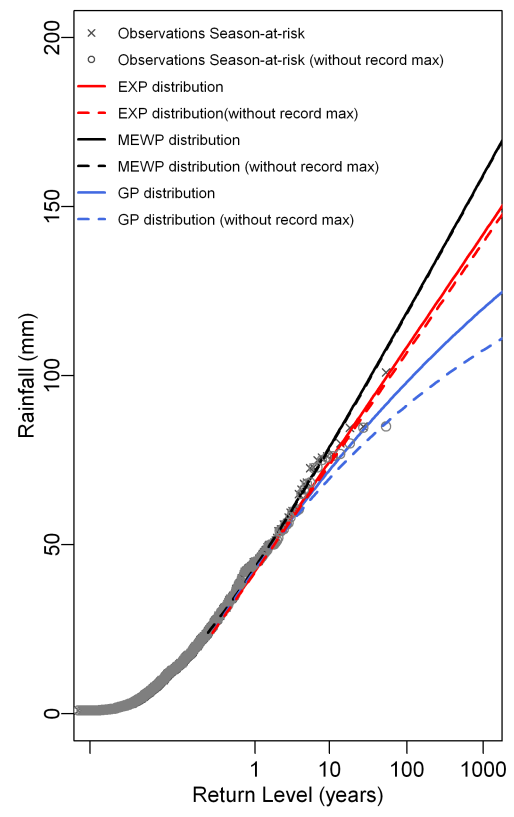

Fig. 10. Sensitivity of the extreme daily rainfall quantiles to the maximum value recorded by the Lyon rain gauge during the "season-at-risk" (June to November) for each model (EXP, MEWP and GP distribution).
- Use of marginal exponential distributions for each subsample based on a given weather pattern;

- Construction of a versatile compound distribution able to fit various shapes of empirical daily rainfall distributions up to the highest quantile observed, but with a simple and robust approach for asymptotic behaviour.

An important concern was to approach the "i.i.d." hypothesis of heavy rainfall samples. Independence of highest values is quite easy to ensure, but the homogeneity of subsamples has to be checked indirectly:

- A priori, considering the discriminating power of the WP classification, it should be checked that the chosen classification minimizes deviation within classes, and maximizes it between classes;

- A posteriori, regarding the strong variability of rainfall asymptotic behaviours induced by the WP subsampling.

Based on relevant sub-sampling of rainfall observations, our study shows that the exponential distribution can reasonably be used to describe the asymptotic behaviour of each sub-sample. A combination of those exponential distributions based on regional climatology, can adequately fit rainfall distributions showing Pareto behaviour $(\xi>0)$ for observable quantiles. In this connection, the behaviour for observable quantiles is not necessarily transposable to extreme 

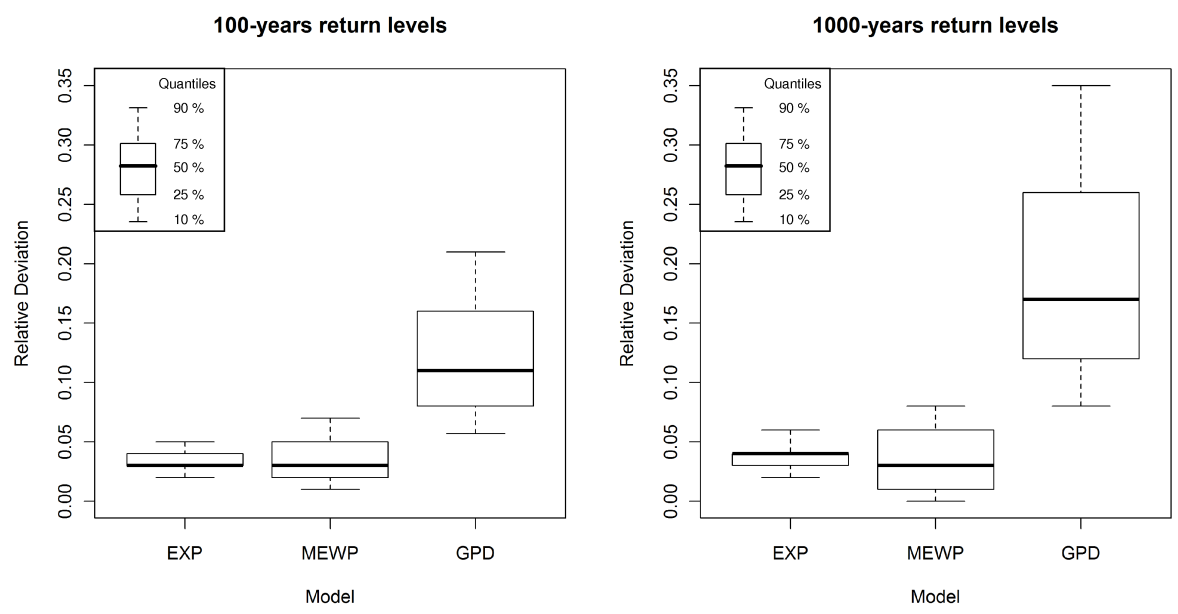

Fig. 11. Relative deviation between two estimations of the100-years (left) and 1000-years (right) return levels. For each model (EXP, MEWP and GP distribution) the two estimations are computed on the "season-at-risk", with and without the observed maximum. The box plots show the spread of the results for the 478 rain gauges.

quantiles. The proposed sampling method and the associated probabilistic model were presented and illustrated using the daily rainfall records for Lyon and St Etienne en Dévoluy. Some simple tests have been presented to assess the robustness and the accuracy of the proposed model. A more complete comprehensive statistical study of this approach, based on the introduced dataset of 478 rainfall time series, with a special focus on accuracy, will be presented in a future paper.

Acknowledgements. We acknowledge the E-OBS dataset from the EU-FP6 project ENSEMBLES (http://www.ensembles-eu.org) and the data providers in the ECA\&D project (http://eca.knmi.nl). We also thank the CERFACS team for providing the classification developped by J. Boé.

Edited by: H. Cloke

\section{References}

Arnaud, P., Lavabre, J., Sol, B., and Desouches, Ch.: Régionalisation d'un générateur de pluies horaires sur la France métropolitaine pour la connaissance de l'aléa pluviographique, Hydrolog. Sci. J., 53, 34-47, 2006 a.

Arnaud, P., Lavabre, J., Sol, B., and Desouches, Ch.: Cartographie de l'alea pluviométrique de la France Colloque SHF: Valeurs rares et extrêmes de débit pour une meilleure maîtrise des risques, Lyon 15-16 March, 67-80, 2006b.

Arnaud, P., Fine, A., and Lavabre, J.: An hourly rainfall generation model applicable to all types of climate, Atmos. Res. 82, 230242, 2007.

Bardossy, A., Duckstein, L., and Bogardi, I.: Fuzzy rule-based classification of atmospheric circulation patterns, Int. J. Climatol., 15, 1087-1097, 1995.
Boé, J.: Changement global et cycle hydrologique: une étude de régionalisation sur la France, $\mathrm{PhD}$ Thesis, University Paul Sabatier Toulouse III, Pp 256, Toulouse, 2007.

Boé, J. and Terray, L.: A weather type approach to analysing winter precipitation in France: twentieth century trends and influence of anthropogenic forcing, J. Climate, 21, 3118-3133, 2008.

Boughton, W. and Droop, O.: Continuous simulation for design flood estimation - a review, Environ. Modell. Softw., 18, 309318, 2003.

Coles, S.: An introduction to statistical modeling of extreme values, Springer, London, 2001.

Coles, S., Perricchi, L., and Sisson, S.: A fully probabilistic approach to extreme rainfall modelling, J. Hydrol., 273, 35-50, 2003.

Djerboua, A. and Lang, M.: Scale parameter of maximal rainfall distribution: comparison of three sampling techniques, Revue des Sciences de l'Eau, 20, 111-125, 2007.

Efron, B.: Bootstrap methods: Another look at the jackknife, The Annals of Statistics?, 7, 1-26, 1979.

Gottardi, F.: Estimation statistique et réanalyse des précipitations en montagne, $\mathrm{PhD}$ Thesis, Polytechnic Institute of Grenoble, pp 252, Grenoble, 2009.

Guilbaud, S. and Obled, C.: Daily quantitative precipitation forecast by an analogue technique: optimisaion of the analogy criterion, C. R. Acad. Sci. Paris, Earth Planet. Sci., 327, 181-188, 1998.

Haylock, M. R., Hofstra, N., Klein Tank, A. M. G., Klok, E. J., Jones, P. D., and New, M.: A European daily highresolution gridded data set of surface temperature and precipitation for 1950-2006, J. Geophys. Res., 113, D20119, doi:10.1029/2008JD010201, 2008.

Hess, P. and Brezowsky, H.: Katalog der Grosswetterlagen Europas, Bibliothek des Deutschen Wetterdienstes in der US-Zone 33, 39 pp., 1952.

Hirschboeck, K. K.: Hydroclimatically-defined mixed distributions in partial duration flood series, Hydrologic Frequency Modeling, 199-212, 1987. 
Klemeŝ, V.: Probability of extreme hydrometeorological events - a different approach, Extreme Hydrological Events: Precipitation, Floods and Droughts, Proceedings of the Yokohama Symposium, IAHS Publ., 213, 1993.

Koutsoyiannis, D.: Statistics of extermes and estimation of extreme rainfall: I. Empirical investigation of long rainfall records, Hydrolog. Sci. J., 49, 591-610, 2004.

Lang, M. and Desurosne, I.: Esquisse des risques de crues à 1' échelle euro-méditerranéenne: les premiers résultants du programme FRIEND-AHMY exploitant les modéles AGREGEE et TPG, 23emes Journées de 1' hydrauliques, Congrès SHF Crues et Inondations, Nîmes 14-15-16 September, 1994.

Lang, M., Ouarda, T. B. M. J., and Bobée, B.: Towards operational guidelines for over-threshold modeling, J. Hydrol., 225, 103-117, 1999.

Littmann, T.: An empirical classification of weather types in the Mediterranean Bassin and their interrelation with rainfall, Theor. Appl. Climatol., 66, 161-171, 2000.

Madsen, H., Rosbjerg, D., and Harremoës, P.: Application of the Bayesian approach in regional analysis of extreme rainfalls. Stochastic Environmental Research and Risk Assessment, 9, 7788, 1995.

Martinez, C., Campins, J., Jansà, A., and Genovès, A.: Heavy rain events in the Western Mediterranean: an atmospheric pattern classification, Adv. Sci. Res., 2, 61-64, 2008.

Obled, C., Bontron, G., and Garçon, R.: Quantitative precipitation forecasts: a statistical adaptation of model outputs though an analogues sorting approach, Atmos. Res., 63, 303-324, 2002.

Paquet, E., Gailhard, J., and Garçon, R.: Evolution of GRADEX method: improvement by atmospheric circulation classification and hydrological modelling, La Houille Blanche, 5, 80-90, 2006.
Petrow, Th., Merz, B., Lindenschmidt, K.-E., and Thieken, A. H.: Aspects of seasonality and flood generating circulation patterns in a mountainous catchment in south-eastern Germany, Hydrol. Earth Syst. Sci., 11, 1455-1468, doi:10.5194/hess-11-14552007, 2007.

Pujol, N., Neppel, L., and Sabatier, R.: Regional tests for trend detection in maximum precipitation series in the French Mediterranean region, Hydrolog. Sci. J., 52, 956-973, 2008.

Ramos, M. H., Sèns̀i, S., Creutin, J.-D., Morel, C.: Contribution of satellite and lightning data to convective rainfall frequency analysis, IAHS Publication, 270, 233-239, 2001.

Ribatet, M., Sauquet, E., Gresillon, J., and Ouarda, T. B. M. J.: Usefulness of the Reversible Jump Markov Chain Monte Carlo Model in Regional Flood Frequency Analysis, Water Resour. Res., 43, W08403, doi:10.1029/2006WR005525, 2007.

Romero, R., Sumner, G., Ramis, C. and Genoves, A.: A classification of the atmospheric circulation patterns producing significant daily rainfall in the Spanish Mediterranean area, Int. J. Climatol., 19, 765-785, 1999.

Rosbjerg, D. and Madsen, H.: Advanced approaches in PDS/POT modelling of extreme hydrological events in Hydrology: Science \& Practice for the 21th Century, 217-221, British Hydrological Society, London, 2004.

Shanbhag, D. N.: The Characterizations for Exponential and Geometric Distributions, J. Amer. Statist. Assoc., 65, 1256-1259, 1970.

Teweles, J., Wobus, H.: Verification of prognosis charts, Bull. Am. Meteorol. Soc., 35(10), 455-463, 1954.

Yarnal, B., Comrie, A. C., Frakes, B., and Brown, D. P.: Developments and prospects in synoptic climatology, Int. J. Climatol., 21, 1923-1950, 2001. 